Journal of Animal and Veterinary Advances 11 (19): 3512-3516, 2012

ISSN: $1680-5593$

(C) Medwell Journals, 2012

\title{
VEGF/VEGFR-2 mRNA Expression in a Mouse Menstrual-Like Model by Pharmacologic Progesterone Withdrawal
}

\author{
Xiangbo $\mathrm{Xu}$ and Bin $\mathrm{He}$ \\ Reproductive Physiology Laboratory, National Research Institute for Family Planning, \\ 100081 Beijing, People's Republic of China
}

\begin{abstract}
Vascular Endothelial Growth Factor (VEGF)/Vascular Endothelial Growth Factor Receptor 2(VEGFR2) are vital in menstruation. This study aimed to explore their expressions in a mouse menstrual-like model by pharmacologic progesterone withdrawal. A mouse model was prepared by administration of mifepristone after decidualization of ovariectomized mice. Semiquantive-PCR and in situ hybridization were performed to the expression patterns of VEGF/VEGFR-2 mRNA. VEGF mRNA peaked at $24 \mathrm{~h}$ and obviously reduced at other time points. VEGF mRNA was mainly located in the basal zone from $0-24 \mathrm{~h}$, epithelium and stroma zone from 32-48 h. VEGFR-2 mRNA was higher at 0 and $40 \mathrm{~h}$ rather weak at 8,16 and $32 \mathrm{~h}$, nearly not expressed at 24 and $40 \mathrm{~h}$. VEGFR-2 mRNA was strongly located in the basal zone at 0,8 and $16 \mathrm{~h}$ in the epithelium zone at 24,32 and $48 \mathrm{~h}$ and epithelium and stroma zone at $40 \mathrm{~h}$. The locations of VEGF/VEGFR-2 in mouse menstrual-like model displayed regional character.
\end{abstract}

Key words: Vascular Endothelial Growth Factor (VEGF), Vascular Endothelial Growth Factor Receptor 2 (VEGFR2), mouse menstrual-like model, pharmacologic progesterone withdrawal, epithelium

\section{INTRODUCTION}

Menstruation is a unique character of primate; in which endometrium undergo breakdown and following the repair. The detailed mechanism of menstruation was not further explored, partly lack of suitable animal model. Two models of menstrual like in mice, a mammalian species which does not menstruate naturally were established.

Mouse menstrual-like model was first established in the 1980s (Finn and Pope, 1984). The model was optimized by Salamonsen's group (Finn and Pope, 1984). In the laboratory, a mouse menstrual-like model induced by pharmacological progesterone withdrawal was established in which pharmacological progesterone withdrawal by mifepristone administration instead of physiological progesterone withdrawal was applied (Xu et al., 2007). The duration of the endometrium breakdown and shedding in the two models were identical in which tissue breakdown was marked by $16 \mathrm{~h}$, the decidual zone shed by $24 \mathrm{~h}$ with bleeding, endometrium began to repair at $32 \mathrm{~h}$ and regenerated completely within $48 \mathrm{~h}$. Furthermore, to date, the mouse menstrual-like models have been widely accepted in the study of endometrial breakdown and also validated for its reliability of studying menstruation mechanism.
Vascular Endothelial Growth Factor (VEGF) was known to be required for normal as well as pathological angiogenesis in many tissues, moreover, the action of VEGF are primarily mediated by 2 transmembrane tyrosine kinase receptors, VEGF Receptor 1 (VEGFR-1 or Flt1) and VEGF Receptor 2 (VEGFR-2 or Flk1) (Wulff et al., 2001). In the rhesus macaque, expression of VEGF was heightened in the newly formed surface epithelium and in the regenerating stroma during the postmenstrual repair and early proliferative phases. Importantly, blockade of VEGF blocked reepithelialization in both the postmenstrual endometrium in thesus macaque and mouse uterus after decidual breakdown (Nayak and Brenner, 2002). Though the expression patterns of VEGF were explored in rhesus macaque, the corresponding data especially the expression pattern of VEGFR-2 in the mouse model were lack till now.

Researchers hypothesis that the expressions patterns of VEGF and VEGFR-2 in the mouse model were also strongly related to the function of endometrium repair. The amount and location of VEGFR-2 in the mouse menstrual-like model induced by pharmacological block of progesterone were studied in the present study. A similar distribution was in the rhesus macaque menstruation model. The similarities and differences in the two models were discussed.

Corresponding Author: Xiangbo Xu, Reproductive Physiology Laboratory, National Research Institute for Family Planning, 100081 Beijing, People's Republic of China 


\section{MATERIALS AND METHODS}

Animals: Female virgin C57 mice 8-12 weeks old were obtained from the Animal Services of the National Research Institute for Family Planning. Mice were kept under controlled light (lights on from 0600-1800) and temperature $\left(21 \pm 1^{\circ} \mathrm{C}\right)$ and allowed free access to food and water. Experimental and surgical procedures were approved by the Animal Ethics Committee of National Research Institute for Family Planning (Approval ID: 20100318).

Induction of the mouse menstruation model: The manipulation of the animals followed the procedure described by Xu et al. (2007) as shown in Fig. 1. Animals were ovariectomized under anesthesia and allowed to recovery for 1 week. On days 1, 2 and 3, all mice were subcutaneously (s.c.) injected daily with $100 \mathrm{ng}$ of $17 \beta$-estradiol (E2) (Alfa Aesar Inc., Heysham, UK) in arachis oil at $0930 \mathrm{~h}$. After resting for 3 days, progesterone implants were inserted s.c. into the back of each mouse at $0930 \mathrm{~h}$ on day 7 and $50 \mathrm{ng}$ of progesterone (Sigma-Aldrich Inc., St. Louis, MO, USA) and 5 ng of $17 \beta-\mathrm{E} 2$ in arachis oil were also injected s.c. On days 8 and $9,5 \mathrm{ng}$ of $17 \beta-\mathrm{E} 2$ in arachis oil was injected s.c. at $0930 \mathrm{~h}$. On day 9 at $1130 \mathrm{~h}, 20 \mu \mathrm{L}$ of arachis oil was injected into the lumen of the left uterine horn of each mouse through a dorsal incision to induce decidualization. The right horn was not treated with arachis oil and served as a negative control.

After $48 \mathrm{~h}, 120 \mathrm{mg} \mathrm{kg}^{-1}$ mifepristone (Beijing Zizhu Pharmaceutical Co., Ltd. Beijing, China) was given to the mouse by intragastric administration at $1130 \mathrm{~h}$ (regarded forthwith as $0 \mathrm{~h}$ ). Mice were sacrificed by cervical dislocation at $0,8,16,24,32,40$ and $48 \mathrm{~h}(\mathrm{n}=10$ for each time point) after mifepristone administration, uterine horns were harvested at each time interval and fixed in $4 \%$ paraformaldehyde, three sections each mice were for analysis of histomorphology and immunohistochemistry.

Semi-quantitive PCR analysis of VEGF and VEGFR-2 mRNA: Total RNA from uterus was treated with DNase, $2 \mu \mathrm{g}$ RNA was reverse transcribed with M-MLV reverse transcriptase using hexanucleotides to prim the reaction. The first strand cDNA was used as templates for RT-PCR. VEGF and VEGFR-2 specific primers were, respectively designed: VEGF: forward 5'GCTACTGCCGTCCGATTGAGA-3' and reverse 5'TCACCGCCTTGGCTTGTC-3'. VEGFR2: forward 5'GCTCACAGGCAACATCGG-3' and reverse 5'TCATAAGGCAAGCGTTCA-3'. GAPDH was used as
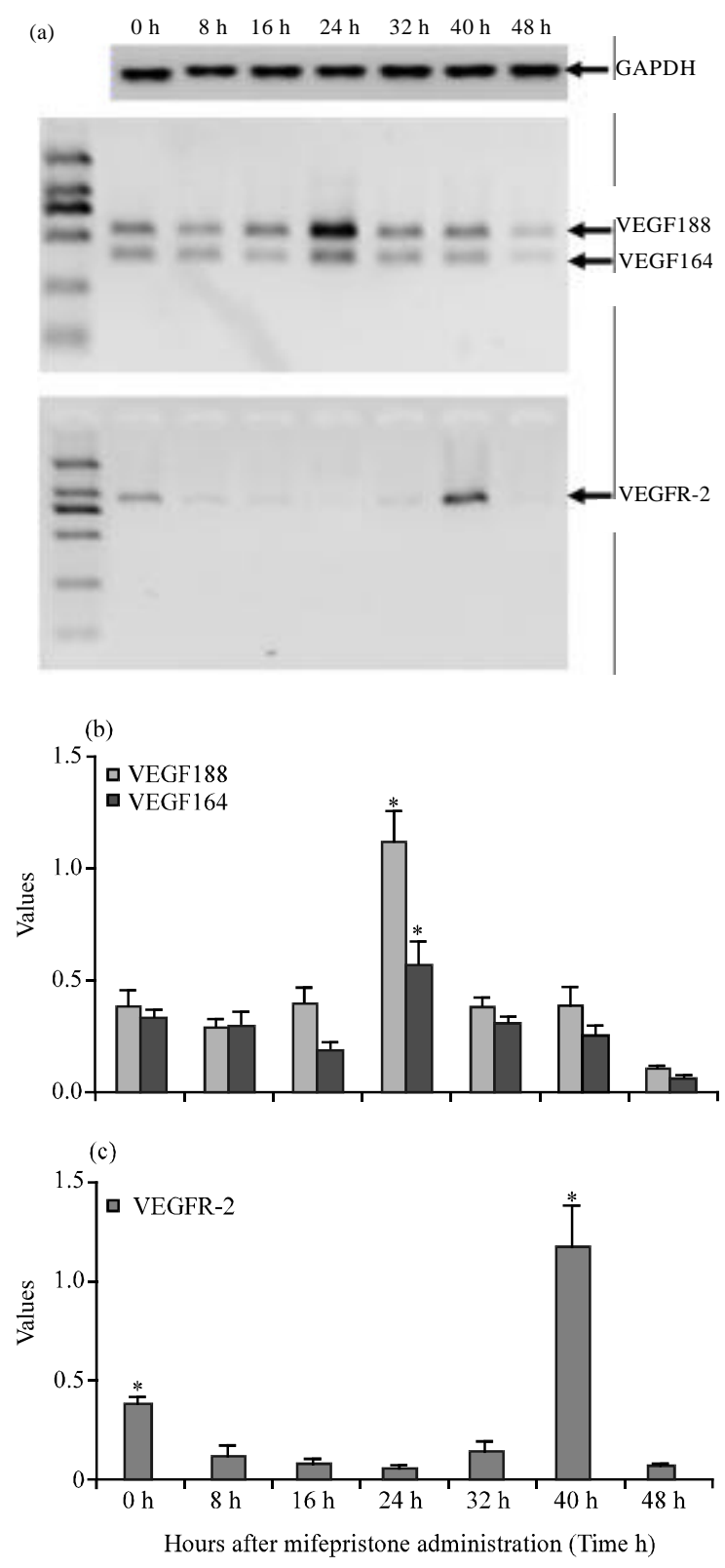

Fig. 1a-c): The changes of VEGF/VEGF-R2 mRNA in mouse menstrual-like model from $0-48 \mathrm{~h}$ after progesterone withdrawal

the internal control and its primer: forward 5'AAATTCAACGGCACAGTCAA-3' and reverse 5'TCCACGAC-ATACTCAGCACC-3'. The PCR cycling parameters were one cycle of $94^{\circ} \mathrm{C}$ for $5 \mathrm{~min}, 28$ cycles of $94^{\circ} \mathrm{C}$ for $30 \mathrm{sec}, 54^{\circ} \mathrm{C}$ for $30 \mathrm{sec}$ and $72^{\circ} \mathrm{C}$ for $1 \mathrm{~min}$ with a final extenssion step of $72^{\circ} \mathrm{C}$ for $10 \mathrm{~min}$. The RT-PCR products were analyzed by electrophoresis on $1.5 \%$ agarose gel with PCR products. All reactions were performed in triplicate. 
Table 1: VEGF/R2 oligonucleotide probes for in situ hybridization Oligonucleotide probes

$\begin{array}{ll}\text { Genes } & \text { Oligonucleotide probes sense } \\ V E G F & \text { 5DigGCATGGTGGAGGTA } \\ & \text { CAGCAGTAAAGCCAG }\end{array}$

$V E G F R-2 \quad$ 5' Dig GTAGGCTCCAGT ATCATTTC CAACCAC anti-sense 5' Dig TGCACTGGAC CC TGGCTTTA CTGC T GTA CC TCCACCATGC 5' Dig GAGATACTTCAC AGG GATTCGGACTTG

In situ hybridization analysis of VEGF and VEGFR-2 mRNA: In situ hybridization analysis of VEGF and VEGFR-2 mRNA in mouse endometrium was performed as earlier described. For ISH assays, $3 \mu \mathrm{m}$ tissue sections were deparaffinized and rehydrated by incubations in graded alcohol solutions. Digestion was performed with Proteinase $\mathrm{K}$ for $30 \mathrm{~min}$. After the section was incubated with pre-hybridization mixture at $42^{\circ} \mathrm{C}$ for $2-4 \mathrm{~h}$, the section was added with the hybridization probe and incubated at $42^{\circ} \mathrm{C}$ overnight. Before adding the hybridization probe, it was denatured $95^{\circ} \mathrm{C}$ for $5 \mathrm{~min}$. the coverslip was removed and the slide was washed in $50 \%$ formamide: $2 \times \mathrm{SSC}$ at $37^{\circ} \mathrm{C}$ for $5 \mathrm{~min}$ each three times and an additional wash was performed in $0.5 \times \mathrm{SSC}$ and $0.2 \times \mathrm{SSC}$ at $37^{\circ} \mathrm{C}$ for $15 \mathrm{~min}$ twice. For detection of digoxigenin-labeled hybridized probe, sections were blocked with $10 \%$ fetal calf serum and $10 \%$ normal sheep serum for $20 \mathrm{~min}$ and then incubated with alkaline phosphatase-conjugated sheep anti-digoxigenin IgG for $1 \mathrm{~h}$ at RT. The color was developed in the dark with the chromogenic agents NBT, X-phosphate and $2 \mathrm{mM}$ levamisole (Table 1).

Statistical analysis: The results are expressed as means \pm SEM. Statistical analysis of quantitative data was performed by the Student's t-test. The $\mathrm{p}<0.05$ was regarded as significant.

\section{RESULTS AND DISCUSSION}

Semi-quantitive PCR analysis of VEGF and VEGFR-2 mRNA: VEGF mRNA expression level were explored at $0,8,16,24,32,40$ and $48 \mathrm{~h}$ in the mouse model. Two splice variants of VEGF including VEGF188 and VEGF164 existed, VEGF188 mRNA was higher thatVEGF164 and the changes of tendency of the two was similar that is they kept a low level at 0,8 and 16 and sharply increased at $24 \mathrm{~h}$ then obviously reduced at $32 \mathrm{~h}$ and returned to the low level as 0,8 and 16 at 32,40 and $48 \mathrm{~h}$. VEGFR-2 mRNA was expressed at $0 \mathrm{~h}$ then reduced to a very low level at 8, 16, 24 and $32 \mathrm{~h}$ after that VEGFR-2 was sharply increased at $40 \mathrm{~h}$ and also returned a very low level at $48 \mathrm{~h}$. In addition, house-keeping genes GAPDH expressed unchanged during the whole period.
In situ hybridization analysis of VEGF and VEGFR-2 mRNA: VEGF mRNA was strongly located in stroma of the basal zone from $0-6 \mathrm{~h}$, meanwhile, it was also in the glandular epithelium and vascular endothelium. With the endometrium further broke down except for the above mentioned position, it was also in stroma of the middle of decidual zone at $24 \mathrm{~h}$. In the period of endometrium repair except for the necrosis zone shedding off into the uterus luminal, new formed luminal epithelium, glandular epithelium and vascular endothelium were also visible at $32 \mathrm{~h}$. At $40 \mathrm{~h}$, the epithelium repaired well and stoma zone began to repair, it was also located in the glandular epithelium, vascular endothelium and stoma under luminal epithelium. Till $48 \mathrm{~h}$ as endometrium finished repairing, it was only confined to all the epithelium zones. However, in the control group, similarly as at $48 \mathrm{~h}$ in the treatment group, it was nearly limited to all epithelium zones during the whole process of mifepristone treatment.

As VEGF mRNA, VEGFR-2 mRNA was strongly located in the stroma, glandular epithelium and vascular endothelium of the basal zone at $0 \mathrm{~h}$, the same locations at 8 and $16 \mathrm{~h}$ were as $0 \mathrm{~h}$ but the positive signal was sharply reduced. The position at $24 \mathrm{~h}$ was similar to VEGF. In the proceeding of repair, it was confined to the new formed luminal epithelium at $32 \mathrm{~h}$ and the luminal epithelium, glandular epithelium and vascular endothelium at 40 and $48 \mathrm{~h}$. However in the control group as VEGF, it was limited to all epithelium zones during the whole process of mifepristone treatment (Fig. 2).

In the study, the expression patterns of VEGF mRNA and VEGFR-2 mRNA were explored, VEGF mRNA peaked at $24 \mathrm{~h}$, did not express $48 \mathrm{~h}$ and obviously reduced at other time points. Meanwhile, VEGF mRNA was mainly located in the basal zone from $0-24 \mathrm{~h}$, epithelium and stroma zone from 32-48 h. VEGFR-2 mRNA was higher at 0 and $40 \mathrm{~h}$ rather weak at 8,16 and $32 \mathrm{~h}$, nearly not expressed at 24 and $40 \mathrm{~h}$. Moreover, VEGFR-2 mRNA was strongly located in the basal zone at 0,8 and $16 \mathrm{~h}$ in the epithelium zone at 24, 32 and $48 \mathrm{~h}$ and epithelium and stroma zone at $40 \mathrm{~h}$

That angiorrhexis and the following vascular repair were the vital character in menstruation. Of the various angiogenic factors described so far, VEGF is a prime regulator of both physiological and pathological angiogenesis (Nap et al., 2004). VEGF played a key role in regulating vascular permeability, forming the new vascular structure, promoting endothelial cell proliferation, migration and differentiation (Nap et al., 2004).

VEGF included 5 different splice variants (Ferrara and Davis-Smyth, 1997). In the study, VEGF188 and VEGF 164 were amplified by the specific primer which was 


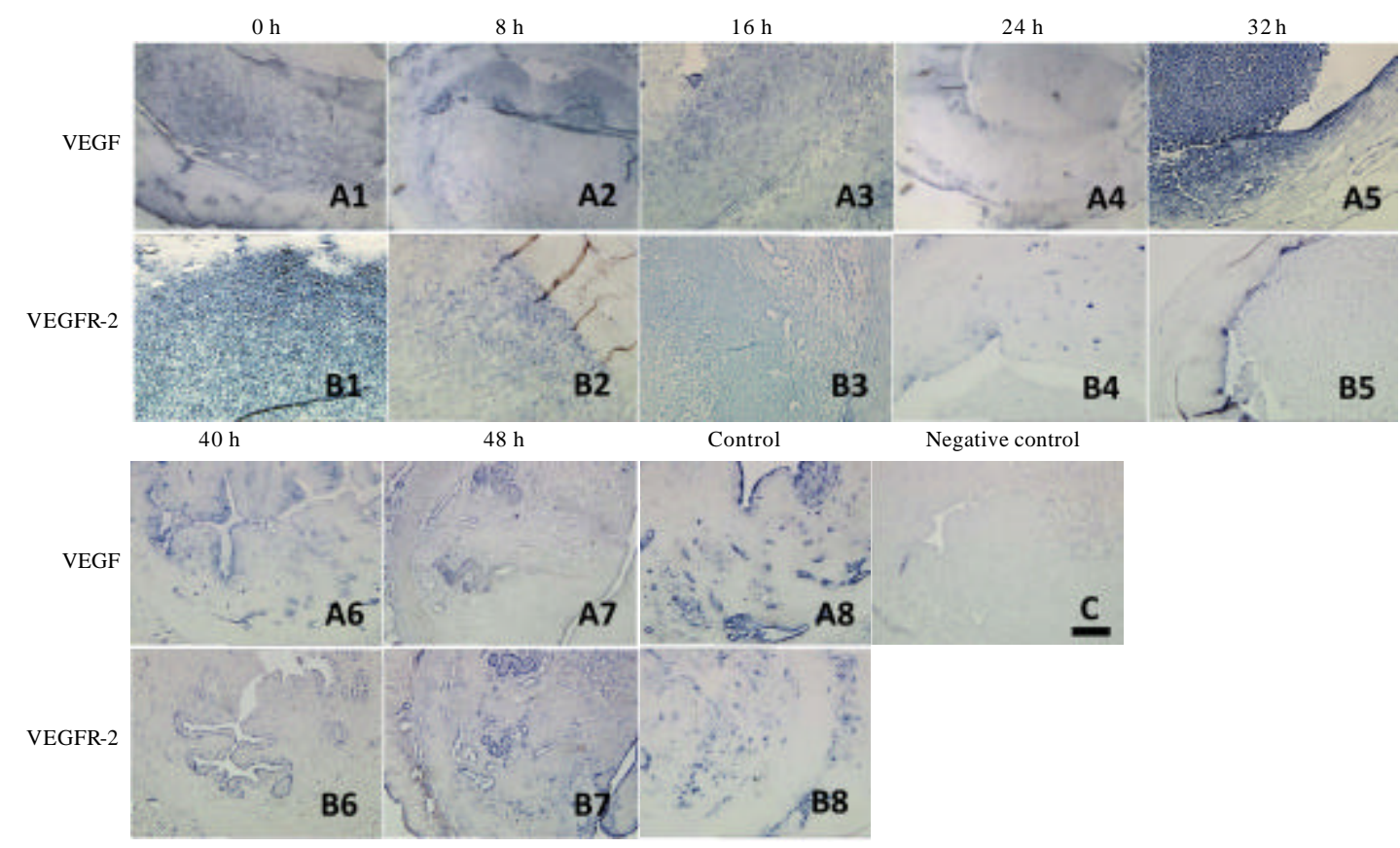

Fig. 2: A1-A7, B1-B7) Typical locations of VEGF and VEGFR-2 mRNA in stimulated uterus in mouse menstrual-like model from $0-48 \mathrm{~h}$ after progesterone withdrawal by in situ hybridization. A8, B8) The location VEGF and VEGFR-2 in unsimulated uterus. C) Negative control

consistent with the earlier study, the splice variants of VEGF existing in mouse were VEGF188 and VEGF164 (Ferrara and Davis-Smyth, 1997).

In the study, VEGF mRNA nearly unchanged during the process and peaked at $24 \mathrm{~h}$ it was just time that endometrium underwent breakdown and shedding, so there was the possibility that VEGF was functional in the process. In fact, VEGF functions by it corresponding receptor, the action of VEGF are primarily mediated by 2 transmembrane tyrosine kinase receptors, VEGFR-1 and VEGFR-2. Although, VEGFR-1 binds to VEGF with high affinity, most of the biological effects of VEGF are mediated by VEGFR-2 (Ferrara and Kerbel, 2005; Roguin and Levy, 2005) here was reason of VEGFR-2 being studied. Though VEGF reached maxium at $24 \mathrm{~h}$ but its effecter VEGFR-2 delayed the high expression at $40 \mathrm{~h}$. For the time being, endometrium was repairing, so VEGF and VEGFR-2 functioned more possible in endometrium repair than break-down which was consistent with the result from rhesus macaque and mouse by VEGF Trap that VEGF plays a key role in endometrium repair (Fan et al., 2008).

In the study, there was also a high level in VEGFR-2 mRNA at $0 \mathrm{~h}$, at the time point, progesterone did not withdraw and endometrium decidualized well, so the status of endometrium was similar to the counterpart of the implantation period (Douglas et al., 2009) in which VEGF/VEGFR-2 in endometrium were vital in regulating the vascular permeability for implantation. Thus, the high expression of VEGFR-2 here was reasonable. The specific role of gene could be suggested by its location in tissue. During the endometrium breakdown and shedding, though VEGF/VEGFR-2 mRNA were also located in the glandular epithelium and vascular endothelium, there were also the same location in control group. However, there was more strong expression in the stroma zone of the basal zone, so the role of VEGF/VEGFR-2 was more possible in the stroma and not epithelium in the process. The finding that supported the corresponding in rhesus macaque (Nayak and Brenner, 2002) in which VEGF mRNA was strongly up-regulated in the stoma of upper zone during the premenstruation. As Brenner supposed, VEGF may play a role in the menstruation induction cascade.

During the endometrium repair in the treatment group, VEGF mRNA was restricted to the epithelium and stroma zones under luminal epithelium however there was also expression in epithelium in control group, so VEGF was more possible related to the stroma repair. In rhesus macaque and human, VEGF expression was increased in the stroma during the proliferative stage. The finding was consistent with (Nayak and Brenner, 2002). In the study, VEGFR-2 mRNA was confined to the luminal epithelium, glandular epithelium and vascular endothelium from $32-48 \mathrm{~h}$ but there was the similar location in the control group. In rhesus macaque and human, VEGFR-2 was 
confined to vasculature (Nayak and Brenner, 2002), so a reasonable explanation was not given for different position of VEFGFR-2 in the mouse and primates.

Reports on the expression of VEGF varied in human, specifically, a study reported that an increase in gland during the secretory and menstrual phages (Charnock-Jones et al., 1993; Shifren et al., 1996; Torry et al., 1996) but others showed no difference across the menstrual cycle (Lau et al., 1999; Li et al., 1994). The inconsistency also existed in the stroma zone (Lau et al., 1999; Li et al., 1994; Shifren et al., 1996; Torry et al., 1996). The big difference may be owing to variations in hormone levels at the time of endometrial sampling or to variations in the region biopsied. To address the limitation, ovariectomized artificially cycling macaques and withdrew $\mathrm{P} 4$ at the end of cycle to provide a starting point for synchronization of endometrial samples (Nayak and Brenner, 2002). However, Macaques was in inferior position of sources, practice, ethical considerations. Mouse as the classical animal model, banished these limitations, so here the finding provided a parallel data for from macaques and the practical worth of the mouse model in study menstruation mechanism was proved.

\section{CONCLUSION}

Expression patterns of VEGF/VEGFR-2 mRNA in mouse menstrual-like model suggesting they were important in the endometrium breakdown and repair, it will favor us to understand the mechanism in menstruation and the disease related to endometrium regeneration.

\section{ACKNOWLEDGEMENTS}

This research was supported by Fundamental Research Funds for the Central Institutes (No. 2009GJSSJKA02) and the National Nature Science Foundation of China (No. 30901608). The funders had no role in study design, data collection and analysis, decision to publish or preparation of the manuscript.

\section{REFERENCES}

Charnock-Jones, D.S., A.M. Sharkey, J. Rajput-Williams, D. Burch and J.P. Schofield et al., 1993. Identification and localization of alternately spliced mRNAs for vascular endothelial growth factor in human uterus and estrogen regulation in endometrial carcinoma cell lines. Biol. Reprod., 48: 1120-1128.

Douglas, N.C., H. Tang, R. Gomez, B. Pytowski and D.J. Hicklin et al., 2009. Vascular endothelial growth factor receptor 2 (VEGFR-2) functions to promote uterine decidual angiogenesis during early pregnancy in the mouse. Endocrinology, 150: $3845-3854$.
Fan, X., S. Krieg, C.J. Kuo, S.J. Wiegand and M. Rabinovitch et al., 2008. VEGF blockade inhibits angiogenesis and reepithelialization of endometrium. FASEB J., 22: 3571-3580.

Ferrara, N. and R.S. Kerbel, 2005. Angiogenesis as a therapeutic target. Nature, 438: 967-974.

Ferrara, N. and T. Davis-Smyth, 1997. The biology of vascular endothelial growth factor. Endocrinol. Rev., 18: 4-25.

Finn, C.A. and M. Pope, 1984. Vascular and cellular changes in the decidualized endometrium of the ovariectomized mouse following cessation of hormone treatment: A possible model for menstruation. J. Endocrinol., 100: 295-300.

Lau, T.M., B. Affandi and P.A.W. Rogers, 1999. The effects of levonorgestrel implants on vascular endothelial growth factor expression in the endometrium. Mol. Human Reprod., 5: 57-63.

Li, X.F., J. Gregory and A. Ahmed, 1994. Immunolocalisation of vascular endothelial growth factor in human endometrium. Growth Factors, 11: 277-282.

Nap, A.W., A.W. Griffioen, G.A. Dunselman, J.C. BoumaTer Steege, V.L. Thijssen, J.L. Evers and P.G. Groothuis, 2004. Antiangiogenesis therapy for endometriosis. J. Clin. Endocrinol. Metab., 89: 1089-1095.

Nayak, N.R. and R.M. Brenner, 2002. Vascular proliferation and vascular endothelial growth factor expression in the rhesus macaque endometrium. J. Clin. Endocrinol. Metab., 87: 1845-1855.

Roguin, A. and A.P. Levy, 2005. Angiogenesis-an update. Pediatr. Endocrinol. Rev., 2: 391-398.

Shifren, J.L., J.F. Tseng, C.J. Zaloudek, I.P. Ryan and Y.G. Meng et al., 1996. Ovarian steroid regulation of vascularr endothelial growth factor in the human endometrium: Implications for angiogenesis during the menstrual cycle and in the pathogenesis of endometriosis. J. Clin. Endocrinol. Metab., 81: 3112-3118.

Torry, D.S., V.J. Holt, J.A. Keenan, G. Harris, M.R. Caudle and R.J. Torry, 1996. Vascular endothelial growth factor expression in cycling human endometrium. Fertil. Steril., 66: 72-80.

Wulff, C., S.J. Wiegand, P.T. Saunders, G.A. Scobie and H.M. Fraser, 2001. Angiogenesis during follicular development in the primate and its inhibition by treatment with truncated Flt-1-Fc (vascular endothelial growth factor Trap(A40)). Endocrinology, 142: 3244-3254.

$\mathrm{Xu}$, X.B., B. He and J.D. Wang, 2007. Menstrual-like changes in mice are provoked through the pharmacologic withdrawal of progesterone using mifepristone following induction of decidualization. Human Reproduction, 22: 3184-3191. 